\title{
The Materials Mode in the Local Context of Muğla and the Role of Mother Tongue ${ }^{i}$
}

\author{
Perihan Korkut ${ }^{1, *}$, Abdullah Ertaş ${ }^{2}$ \\ ${ }^{1}$ ELT Department, Faculty of Education, Mugla Sitki Kocman University, Mugla, Turkey \\ ${ }^{2}$ School of Foreign Languages, Atilim University, Ankara, Turkey
}

Copyright $\bigcirc 2017$ by authors, all rights reserved. Authors agree that this article remains permanently open access under the terms of the Creative Commons Attribution License 4.0 International License

\begin{abstract}
Materials mode is one of the four modes of a lesson in the Self Evaluation Teacher Talk (SETT) framework. The aim of this study is to identify the interactional features during the materials mode in Muğla, Turkey. The lessons of English teachers at the state schools and the microteaching presentations of teacher trainees at Muğla Sıtkı Koçman University were recorded, transcribed and analyzed in comparison with the framework. The findings indicate that although the interactional features match to those defined in SETT for the most part, there are also some differences that can be attributed to cultural and local practices. The analysis showed that mother tongue plays an important role in the fulfillment of the pedagogical goals. The findings indicate that mother tongue should be taken seriously in teacher education.
\end{abstract}

Keywords Classroom Discourse, Teacher Talk, Mother Tongue, Teacher Education, Materials Mode

\section{Introduction}

Materials are considered incontrovertibly important aspect of teaching a language. The two possibilities are for teachers to make their own materials or to use published textbooks. More often than not, the teachers prefer using a published textbook as materials in their lessons because of a few reasons. First of all, they are prepared by experts. Therefore, the units in a textbook are not only more attractive by design, but also designed as a part of a coherent syllabus and with satisfactory language control. Secondly, they come with extra materials and teachers' guides which tell what to do for extension which save the teacher from lots of preparation time. Moreover, the textbook can be useful for teacher development, especially at times of methodological change [10].

However, materials cannot bring about change on their own. By analyzing the materials in terms of goals, content, method and guidance, Allwright [2] demonstrated that it is hard to imagine teacher-proof materials. Because there are so many decisions to be taken and every issue cannot possibly be addressed with pre-packaged decisions. The teachers do not follow the textbook in a slavish manner. They make changes in order to fit the textbook to the particularities of their situation or to appeal to their own teaching styles and preferences. Thus, the same material can be used very differently in each situation and produce very different results. Especially in Turkey, the native language is an important means of making sense of the textbook materials although it might not be advised by its writers.

The purpose of this paper is to describe and compare how teachers and teacher trainees use textbooks in their lessons. In order to handle the situation, a modes analysis is undertaken based on Walsh's [26] Self Evaluation Teacher Talk framework (SETT hereafter). The mode in SETT which is related to the use of textbooks is called the materials mode. Transcripts of lessons by both English teachers working at state schools (teachers hereafter) and teacher trainees studying at Muğla Sitkı Koçman University (trainees hereafter) are analyzed in terms of the pedagogical purposes and interactional features during the materials mode to be compared to the descriptions in SETT.

The results reported here are part of a larger study (Korkut, 2015) in which the lessons of teachers and trainees were compared in terms of all of the four modes in the SETT framework to propose content for the English Language Teacher Education programme in Turkey.

SETT was developed by close examination of a database of lesson transcriptions which took place in a British university. The framework was also used for research purposes in many other contexts such as Japanese college [9], college writing lessons in Iran [12], and foreign language schools in Turkey [1]. It describes and captures the practices of classroom usage of materials arguably well. Therefore, the comparison of the descriptions in SETT with the lessons by the participants of this study can reveal a picture of the current local practices in terms of the materials mode in the local context of Muğla.

In this article, answers to the following questions were sought: 
1) In what ways is the materials mode in the data similar to or different from the description in SETT?

2) What is the role of students' native language during the materials mode?

3) Are there any differences in the materials mode in T's data and TR's Data?

\subsection{Materials Mode}

Materials mode is one of the four modes defined in SETT. A mode is defined as "an L2 classroom micro-context that has a clearly defined pedagogic goal and distinctive interactional features determined largely by a teacher's use of language" [26]. The four distinct modes are managerial mode, skills and systems mode, classroom context mode and materials mode. Each mode is distinguished by the pedagogic purposes and interactional features.

Materials mode happens when the lesson is focused on a piece of material, or task. The attention of the students is typically focused on the material or the task at hand. There might be a certain type of interaction that the material requires, or the teacher might decide how the interaction will take place. For example, when the students are doing a course book exercise, we can say that the lesson is going on in the materials mode. The teacher conducts the exercises and accepts or rejects the answers, or outcomes. The pedagogical functions and the interactional features during this mode are shown in Table 1 below.

Table 1. The Pedagogical Functions and the Interactional Features in Materials Mode

\begin{tabular}{|l|l|}
\hline Pedagogical Functions & Interactional Features \\
\hline To provide language practice around a & Predominance of IRF \\
piece of material & pattern \\
To elicit responses in relation to the & Extensive use of display \\
material & questions \\
To check and display answers & Form-focused feedback \\
To clarify when necessary & Corrective Repair \\
To evaluate contributions & The use of scaffolding \\
\hline
\end{tabular}

\section{2. $\mathrm{L} 1$ in the $\mathrm{L} 2$ Classroom}

There are differing opinions about whether the native language of students must be avoided or not. According to Ellis [3] the difference stems from different theoretical frameworks. The interactionist perspective holds that maximum exposure to input is required for acquisition. Thus, L2 instead of L1 must be preferred at all costs. Sociocultural theory, on the other hand, accepts L1 use as a valuable cognitive tool for scaffolding L2 production. In addition, theories of motivation also support L1 use [3].

Many teacher training books put forward both the advantages and disadvantages of using the students' L1. Harmer [6] makes the case for a careful and measured use of L1. There are benefits of using L1; it can be used for strategy training, students' language awareness can be increased when they notice the differences between their mother tongue and the target language, and allowing them to use their native language can foster a more positive classroom environment. Using the L1 for the most part of the lesson, on the other hand, can be counterproductive since it restricts the exposure to the language, especially during instructions which is an ideal source of comprehensible input [6].

Macaro [16] presents a strong argument in favor of code-switching in the L2 classroom. He points out that many studies on code switching label it as "recourse to L1" and present it as something to avoid. He argues that in fact code-switching is a better communication strategy than repetition and circumlocution [16]. Code-switching and translation to $\mathrm{L} 1$ are common communication strategies in real life non-native to non-native conversations. However, it is banished in the language classroom, in which "real-life like" is an important criterion of quality.

The issue of code switching has also been studied very extensively in Turkey. Most of these studies are focused on the functions of code switching and emphasized the inevitability of using Turkish in the ELT classroom. To my knowledge, the oldest study in this line was Elridge [4] where code switching was not only described as "natural and purposeful phenomenon" (p. 310), but also it is argued that trying to decrease L1 use would not address the problem of lack of target language use since "decreasing mother tongue use in the classroom does not automatically increase the quality and quantity of target language use" (p. 311). Üstünel's [25] investigation of the organization of the code switching in EFL classrooms using conversation analytic method of sequential analysis revealed that code switching serves 12 different pedagogical functions. Her study "supports the claim that L1 is difficult for teachers to avoid, and perhaps more difficult for learners to ignore in the EFL context." Similarly, Sarıçoban [22] found that learners of English think that using Turkish in English lessons is an appropriate and useful academic tool. They expressed their preference for using Turkish rather than having all-English lessons. In Yatağanbaba and Yıldırım's study, [30] code switching is found to be serving for the purposes of translation, metalanguage, asking equivalence, giving instruction and classroom management. Sali [20] found that mother tongue is used for a multiplicity of reasons. In another study which was directed to finding out the problems encountered during the practicum, Sarıçoban [21] presented the finding that reported that teacher trainees criticized the books for not having any translation exercises and this was presented as a problem. So, we can say that in Turkish context it is well established that L1 is inevitable and even desirable. However, the textbooks which are commonly used in Turkey do not incorporate methodologies that address the native language in a systematic way.

\section{Method}

This paper reports a part of a larger study which took place in the context of Muğla city center. Recordings of English lessons were analyzed qualitatively. The data was collected 
from two different types of participants. The first type is the main data, which were collected from a carefully selected team of 10 teachers (T's Data hereafter). All the participants were given nicknames to maintain anonymity and the chosen teachers were $\mathrm{T} 2, \mathrm{~T} 6, \mathrm{~T} 10, \mathrm{~T} 11, \mathrm{~T} 12, \mathrm{~T} 13, \mathrm{~T} 14, \mathrm{~T} 16, \mathrm{~T} 17$, and T19. The second type was collected from trainees (TR's Data hereafter). These trainees were 7 in number and chosen according to convenience sampling technique (TR1, TR2, TR3, TR4, TR5, TR6, and TR7). Teachers' data (T's Data) is 27 hours and 22 minutes long whereas the trainees' data (TR's Data) lasts 18 hours and 37 minutes. All the recordings were transcribed by the researcher and put through modes analysis [26]. To do this, the researcher took an emic perspective and identified the pedagogical function in each teacher turn using next turn proof techniques. Having identified the materials mode in the data according to the pedagogical functions, she checked and compared the interactional features to the descriptions provided in SETT. In order to save space, the findings are discussed via selected extracts from the data.

\section{Results and Discussion}

\subsection{Similarities to SETT}

The interactional features of this mode are described as the frequent occurrence of I-R-F pattern, display questions, form-focused feedback, repair and scaffolding in SETT [26]. The interaction is closely managed by the teacher while the pace and direction is determined by the material [26]. The same interactional features are found in the analysis of Ts Data, for example Extract 1 below:

In this extract, T6 is doing textbook work about the distinction between the simple past tense and the present perfect tense. The IRF pattern, one of the typical interactional features of this mode identified by Walsh [26] is really conspicuous. T6 treats the first (turns 1-6) and the second students (turns 7-14) differently, suggesting sensitivity to individual differences. She feels that the second student needs more scaffolding than the first one. We can see her using echo and cueing to provide scaffolding through turns 8-14. Scaffolding is a typical feature of materials mode according to Walsh [26]. In turn 8, T6 repeats the learner's utterance as a confirmation that he began correctly. In turn 10 , she provides metalinguistic explanation ("marry is the verb here") plus offers choice ("what or who did"). After the student chooses the correct one, she repeats again as confirmation and encouragement to continue in turn 12 . Once the learner finishes the sentence successfully, she repeats the whole sentence again: "yes who did Prince Rainer marry" with a falling tone for the other students to hear in turn 14. We can observe her concern in the production of grammatically correct sentences. This shows us the focus is on form, which is also listed among the interactional features of the materials mode in SETT.

Extract 1. Materials mode in T6's lesson

\begin{tabular}{|c|c|c|}
\hline 1 & $\mathrm{~s} 1$ & $\begin{array}{l}\text { where has er has er bella } \\
\text { freud worked er since } 1990\end{array}$ \\
\hline 2 & $\mathrm{~T} 6$ & $\begin{array}{l}\text { hmm very good where has } \\
\text { freud worked since } 1990 \\
\text { where has she worked }\end{array}$ \\
\hline 3 & S1 & london \\
\hline 4 & $\mathrm{~T} 6$ & in? \\
\hline 5 & $\mathrm{~s} 1$ & in london \\
\hline 6 & $\mathrm{~T} 6$ & $\begin{array}{l}\text { london well done, yes she } \\
\text { er she has worked since } \\
\text { in london yes that's right } \\
\text { the next question orhun } \\
\text { you like to do the next } \\
\text { one }\end{array}$ \\
\hline 7 & s2 & who: : \\
\hline 8 & T6 & [who:: yes who \\
\hline 9 & S2 & $=$ marry \\
\hline 10 & T6 & $\begin{array}{l}\text { marry? marry is the verb } \\
\text { so what or who did }\end{array}$ \\
\hline 11 & s2 & who did \\
\hline 12 & $\mathrm{~T} 6$ & who did, \\
\hline 13 & s2 & he marry \\
\hline 14 & $\mathrm{~T} 6$ & $\begin{array}{l}\text { [yes who did prince } \\
\text { rainer marry. who did he } \\
\text { ferhat? }\end{array}$ \\
\hline 15 & s3 & grace kelly \\
\hline
\end{tabular}

Extract 2 below shows that materials mode can be found in a very similar way in TRs Data, too.

Extract 2. Materials mode from TR5's lesson

1

2

4
S1

TR5

S2

TR5

S2

TR5

S2

s3

TR5

S3

TR5

s3

TR5

S3

TR5

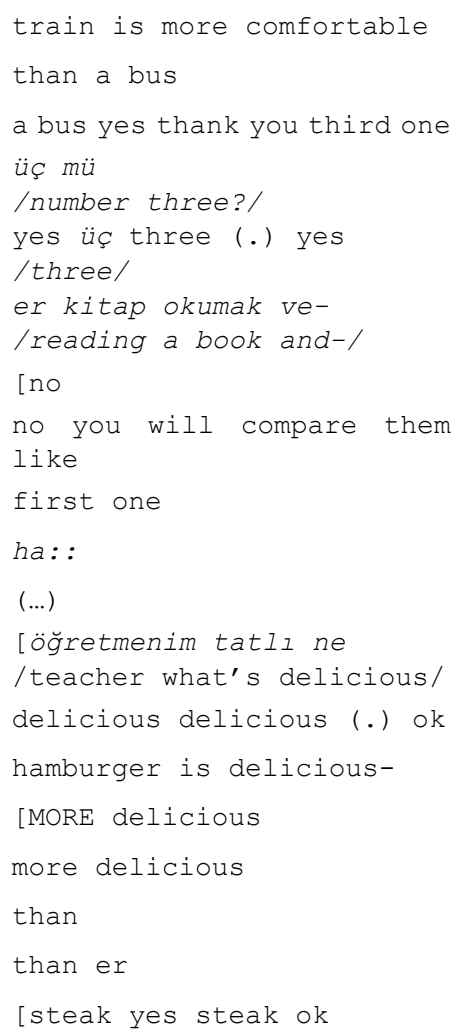


TR5 is conducting a transformation drill presented in the textbook. Again, the interaction goes in the IRF format, although it is broken up by several insertion sequences, "often composed of embedded and nested question-answer adjacency pairs, during which matters relevant to the first part are addressed before the second part is produced" [29]. These insertion sequences happen both with S2 and S3 in this extract. Though not as varied as T6, TR5 also uses some strategies to assist the learner's production by providing the necessary word (turn 9), long explanation (turn 6), recast (turn 11) and cueing (turn 13). It is clearly seen that the focus is on producing a well formed sentence. Once it is provided, TR5 immediately passes on to the other item without any further comments about what has been said.

Other studies in which SETT is used also showed that materials mode is among the most frequent. For example Lee [15] found that the most frequent mode was the materials mode in his data. Similarly, the most frequent modes were materials mode and managerial mode in Wang's [27] data. Also, in Miri and Qassemi's [19] data, materials and skills and systems modes were the most frequent ones. On top of all these, the existence of the same interactional features as the description in SETT in both sets of data strengthens the impression that these features might be universal features that can be found in any language lesson in which materials are used. Nevertheless, the data in this study revealed some other interactional features that are not accounted for in SETT.

\subsection{The Use of $\mathrm{L} 1$}

Students' mother tongue is not accounted for in SETT. However, students' L1 is used for many of the pedagogical goals during materials mode. See the extract 3 below for an example.

Extract 3 contains examples of how the teacher makes use of translation to make the meaning clear (turn 7), and how she asks questions to make sure that students have understood the instructions correctly (turns 3,7 , and 12). In other words, the pedagogic goals of "eliciting responses in relation to the material and clarifying when necessary" [26] are fulfilled in Turkish. According to Willis [28], in the language classroom, language is both the subject of instruction (i.e. "inner structure") and the medium of instruction (i.e. "outer structure"). In outer structures, language is used "to socialize, organize, explain and check, and generally to enable the pedagogic activities to take place" and most of it takes place in the learners' mother tongue where the medium of instruction is not the target language (p.163). T16, then, is observed using the students' mother tongue for outer structures.

Compared with the code switching that takes place in the Extract 2 above, TR5's effort to avoid code switching is evident. Code switching is attempted in two instances by the students, not the trainee. In the first attempt, the student asks for clarification in Turkish: $\ddot{u} c ̧$ mü (number three?) in turn 3 . TR5 uses the Turkish word $\ddot{u} c ̧$ in his response but surrounds it with as much English as possible: "yes $\ddot{u} c ̧$ three yes" in order to emphasize that he prefers English. In addition, we can see a turn interruption in turn 6 , and conspicuously the interrupted turn is in Turkish.

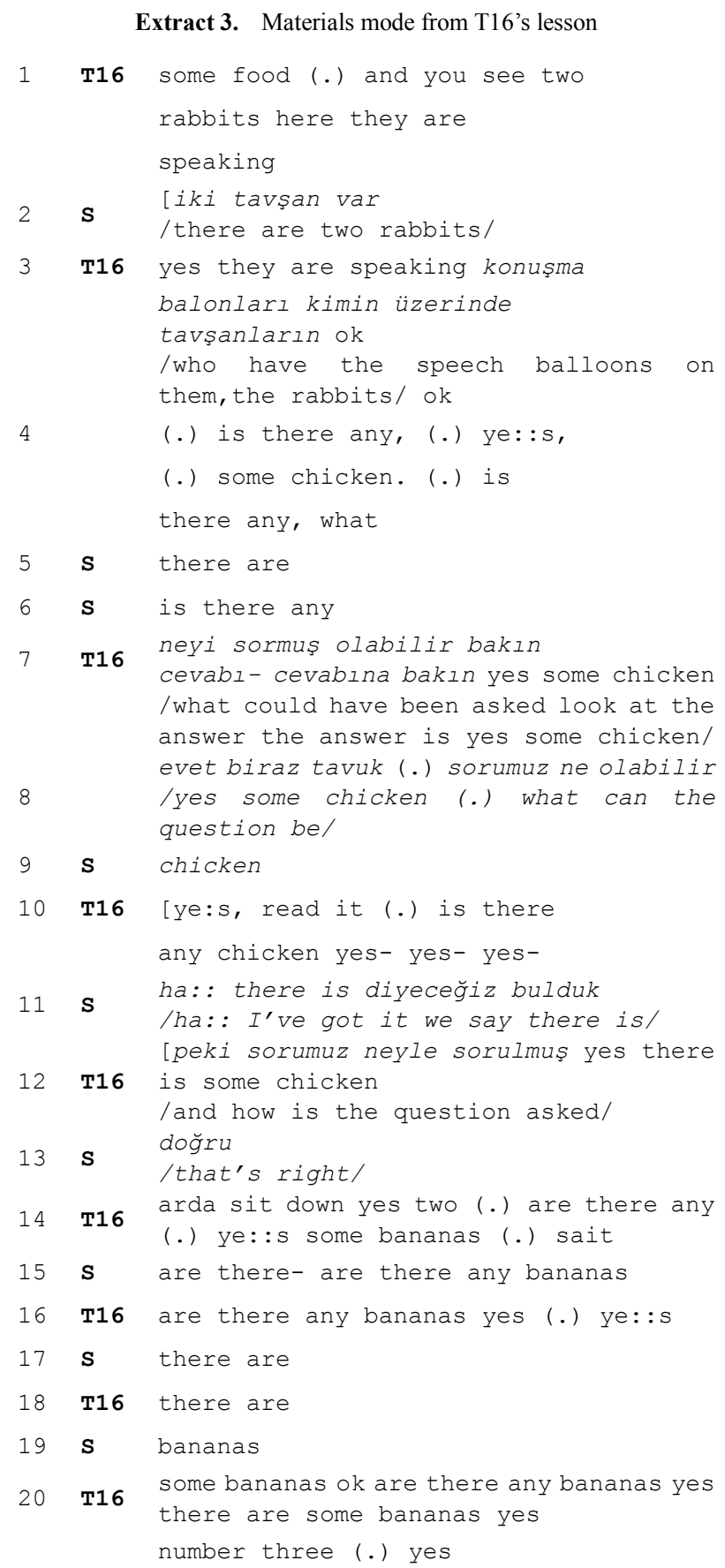

Apparently, Turkish is avoided in TR's data especially when addressing the whole class. This resulted in trainees visit individual desks and talk to individual students privately in Turkish while talking to the whole class in English. This type of language preference cannot be observed in T's data. The following extract comes from another point in TR5's lesson. Since he is talking to individual students, the effort to stay in English, which was observed in the extract 2 , is not evident here. 


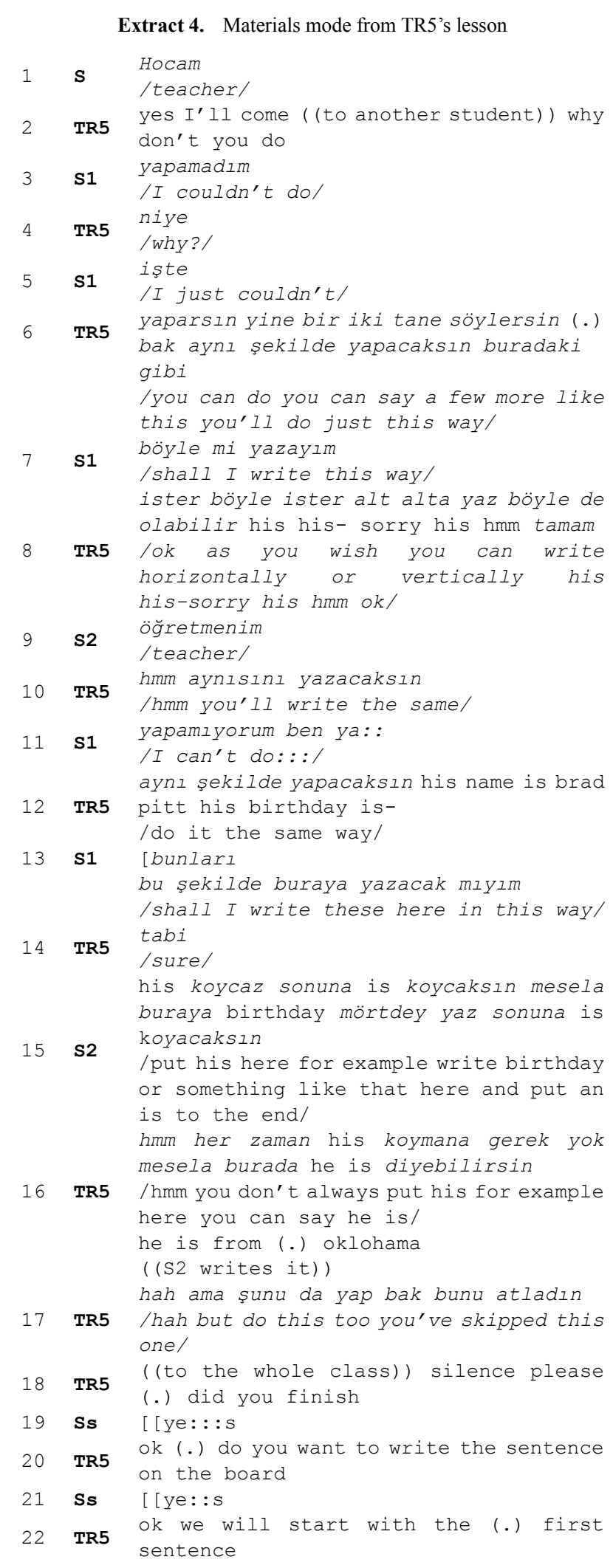

In turn 1, a student calls TR5 for help, since it is audible for all class, he responds in English: "Yes, I'll come". Through turns 3-16, a private conversation between the two students and the trainee takes place, thus we can see lots of Turkish. Here the pedagogic function is providing clarification on the task requirements. After the turn 17, TR5 begins to address the whole class, so he switches back to English. Through turns 3-16, negotiation of meaning takes place as TR5 explains S1 what to do individually. He uses the think-aloud strategy, indicating that he must look at the previous example and do the same thing in turn 6 . S1 asks a clarification request: "böyle mi yazayım" (should I write like this) but he does not find TR5's explanation, which was interrupted by a sequence with S2 through turns 9-10, satisfactory. He expresses his disappointment in turn 11 . This dissatisfaction results in TR5 repeat the key strategy and begin doing the exercise as an example in turn 12. S1 makes another confirmation check in turn 13 which the teacher affirms (turn 14). At that point, S2 who had been overhearing the conversation joins by self-selected turn in turn 15 and makes an explanation. The explanation, however, is flawed and results in TR5's repair turn beginning from turn 16. S1's breakthrough in understanding is shown by his writing the correct answer on the material. As soon as TR5 sees it, he expresses his satisfaction with the token "hah" (in turn 17). After this, he returns to whole class to make the transition to the checking of answers. "Did you finish" in turn 18 serves as a transitional marker which signposts the change from individual work to whole class work. In turn 20, TR5 initiates an extra exchange which requires an answer in chorus as a strategy to gather all students' attention for the next task. The onset of the task is marked in turn 22 where the teacher asserts "we will start with the first sentence".

The difference between Extract 2 and Extract 4 shows clearly that L1 is more acceptable with individual students rather than with the whole class in the TR's Data. The teachers, however, seem not to have such a preference about which utterances should and can be heard by the whole class, as seen in Extract 3. Moreover, this is not the only difference that can be observed between the two sets of data. There are also differences between teachers' lessons and trainees' demo lessons in terms of how the materials are made accessible. Moreover, T's data consists of a hybrid mode which cannot be observed in the TR's Data.

\subsection{Making the Material Accessible}

It was observed that the teachers become an ally of the material during the materials mode, and act as a conductor, who performs the IRF as required by the book. From time to time, however, the teacher becomes an ally of the students, helping them interpret the material and approach the problems, exercises, and tasks introduced by the material. In other words, the teacher serves the function of making the material accessible for the students. This "change of footing" [23] helps teachers to build rapport with the students. In the interactional level, the teacher can take side with the textbook or metaphorically move a step (change foot) next to the student and attack it with various strategies. In order to signal change of footing, the teacher switches the pronoun "you" with "we" [23]. In addition, the teacher may sometimes use "they" while referring to the material, to reflect that the control and authority is delegated to the 
textbook [5].

For example, Extract 3 can be observed to see the change of footing and the choice of language as well. T16 makes sure that the material instruction is understood correctly through turns 1-13. She talks about the material with the pronoun "it" (in turn 7) and refers to the students with "us" (in turns 8 and 12). The preferred language is students' mother tongue. Through turns 14-20 however, she prefers to stay in English because at this point a change in footing occurs. She becomes the voice of the materials, managing the turn taking, evaluating the answers, and conducting the exercise.

In the same vein, when a mismatch between the students' perception and the materials occurs, the teachers change footing and assume the role of negotiator. The preferred language is often L1. To illustrate this point, see the following extract from T14's lesson.

Extract 5. Materials mode from T14's lesson

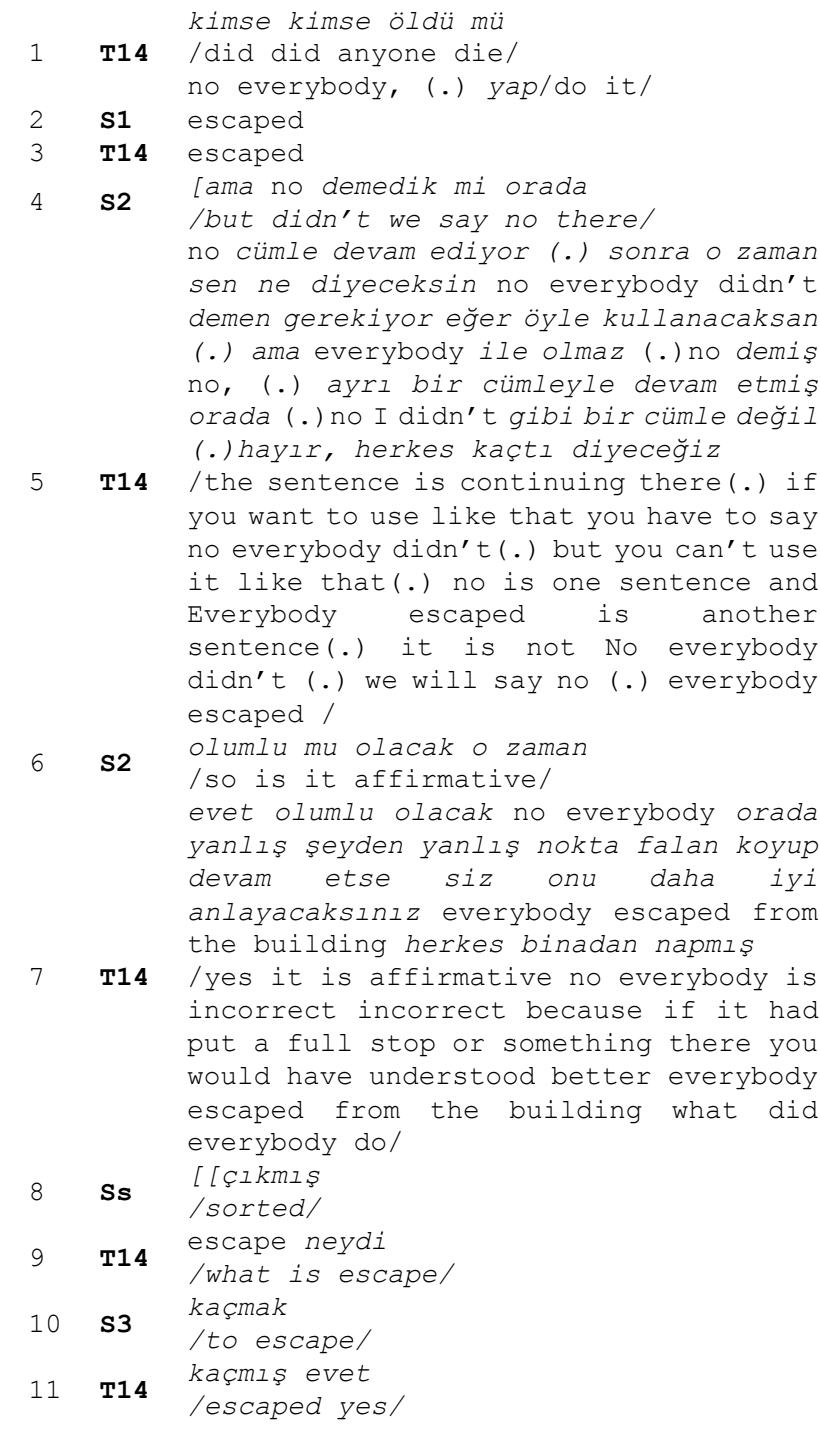

In Extract 5, the students are confused by the fact that the blank in the activity is preceded by a "No", which made them to think that the blank required a negative statement. T14 skillfully handles the situation and makes the necessary explanations through turns 5-7. Notice that she uses the pronoun "it" to refer to the textbook within turn 7 .

Such instances of negotiation tend to happen in Turkish, thus we can find them not during whole class time but during individual feedback in TR's data (See for example extract 4). In addition, a change of footing is not observed for making the material accessible in TR's data. None of the seven trainees had this feature in their observed sessions. Just like TR5 example, trainees seem to assume a role near the materials and against the students even while providing individual help. Both in the extracts 2 and 4, TR5 extensively uses the pronoun "you" to refer to the students. We can examine the following extract from TR3's lesson to further illustrate the lack of change of footing in TRs lessons.

\begin{tabular}{|c|c|c|}
\hline & Extract 6. & Materials mode from TR3's lesson \\
\hline 1 & TR3 & $\begin{array}{l}\text { ((to the whole class)) a pink } \\
\text { pencil with your pencil a pink } \\
\text { pencil a pink pencil }\end{array}$ \\
\hline 2 & s1 & $\begin{array}{l}\text { öğretmenim bunu yazamadım } \\
\text { /teacher I couldn't do this/ }\end{array}$ \\
\hline & TR3 & $\begin{array}{l}\text { tamam sen yazabilirsin } \\
\text { lok you can do it/ }\end{array}$ \\
\hline & TR3 & $\begin{array}{l}\text { ((checking the material)) a } \\
\text { pink pencil hmm (.) hmm pink çok } \\
\text { net çlkmamıs tahtaya a pink- a } \\
\text { pink pencil yazıyorum bakın } \\
\text { /hmm pink is not printed } \\
\text { clearly. I am writing a pink } \\
\text { pencil on the board. Look here/ }\end{array}$ \\
\hline
\end{tabular}

In extract 6, TR3 is warned by a student about a deficiency in the material. In turn 3, her first reaction is in the form of a reassurance that the student can do it. Unlike the teachers in this study, she does not change footing immediately. Upon further inspection, she has to accept that the problem is indeed with the material: apparently, there is a typographical error. But even then she does not use the pronoun 'we'. She remains on the side of the materials.

\subsection{Line-by-line Text Analysis: a hybrid mode?}

So far, the analysis showed that the teacher becomes both the sound of the material (conductor) and the private speech of the students (mediator). There is one more important function in the T's Data, which is not described in SETT: The teachers use the texts in the materials as a resource for line-by-line translation. Using the materials in such a way, namely, to serve as a springboard for vocabulary and grammar teaching via translation, is not among the enlisted pedagogical goals of the materials mode in SETT. Vocabulary and grammar teaching is in fact a pedagogical goal during the skills and systems mode according to SETT. Moreover, these sessions we are about to describe have a "dual focus" whereby they both focus on form and focus on meaning simultaneously [24]. Such focus on meaning is described within the classroom context mode in SETT. In that sense, we might call these translation sessions as a hybrid mode which has the pedagogical function that 
belongs to the materials mode while carrying the interactional features of multiple modes. Walsh [26] acknowledges the possibility of mode-divergence as a result of the culture by stating that:

Given the uniqueness of the L2 classroom and the fact that every interaction is locally produced, it is neither practicable nor realistic to propose that an all- encompassing view of context can be derived, or that an instrument is available which can accurately provide an emic perspective of each interaction.

The following extract comes from T13's lesson. There is a dialogue in the textbook which is intended to serve as a model before pairs make and practice their own dialogues. Before actually doing the pairwork, T13 makes sure that the dialogue is understood by having her students translate it in a line-by-line manner.

xtract 7. Materials mode from T13's lesson

\begin{tabular}{|c|c|c|}
\hline 1 & T13 & $\begin{array}{l}\text { ok (.) ne diyor diyalogda } \\
\text { lok what does it say in the dialogue/ }\end{array}$ \\
\hline 2 & s1 & $\begin{array}{l}\text { bodruma gitmiş } \\
\text { /he went to bodrum/ }\end{array}$ \\
\hline 3 & s2 & $\begin{array}{l}\text { haftasonu nasıld diyor } \\
\text { /it says how was the weekend/ }\end{array}$ \\
\hline 4 & T13 & $\begin{array}{l}\text { hmm weekend ne haftasonu ok how was } \\
\text { his weekend } \\
\text { /hmm what is weekend weekend/ } \\
\text { haftasonu neredeydi mi diyor }\end{array}$ \\
\hline 5 & s1 & $\begin{array}{l}\text { /does it say where was he in the } \\
\text { weekend/ }\end{array}$ \\
\hline 6 & s3 & $\begin{array}{l}\text { hayır it was sunny } \\
\text { /no/ }\end{array}$ \\
\hline 7 & T13 & it was great ha great where were you \\
\hline 8 & S4 & $\begin{array}{l}\text { neredeydin } \\
\text { /where were you/ }\end{array}$ \\
\hline 9 & T13 & $\mathrm{hm} \mathrm{hmm}$ \\
\hline
\end{tabular}

We can see students are trying to make sense of the dialogue. As described in SETT, the interactional space is determined by the type of the activity [26]. The learners seem to have more interactional space during these translation sessions since there happen more than one student turns frequently. For example, from the two suggestions in turns 2 and 3, T13 accepts the latter one by pointing out that weekend is "haftasonu" in Turkish. The students can respond to each other's' contributions freely. For example in turn $6, \mathrm{~S} 3$ warns $\mathrm{S} 1$ that the meaning cannot be "haftasonu neredeydin" (where were you in the weekend) because the answer "it was sunny" does not match it. T13 accepts it as this comment shows the line has been understood, and moves on the next line of the dialogue.

T14 also has her students translate the textbook dialogue. This dialogue is intended to be used as listening material. In the textbook exercise, students are supposed to listen to it from the $\mathrm{CD}$ and answer some comprehension questions. Later on, they will predict the end of the story. T14 spends great effort to make the story comprehensible.

In this extract, we can observe the students' collaborative effort to translate the passage. In turn 4 , one student pays attention to the end of the sentence and combines it with the previous utterance: "iki gün önce konuşmak istedi" ( $\mathrm{He}$ wanted to talk two days ago). T14 draws the student's attention to the word "see" (in turn 5). By this means, she shows the student where to pay attention to and where the important information is. By this way, she is modeling the strategy for the students, also.

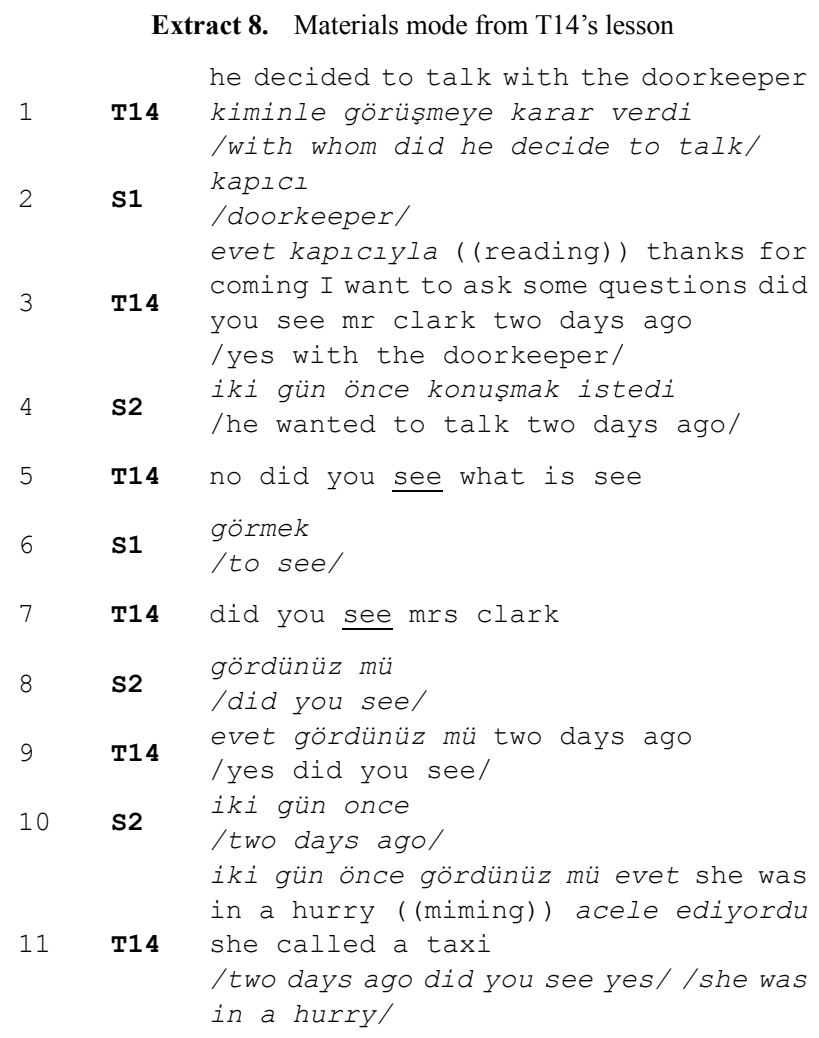

In summary, during these translations many learning opportunities occur, especially strategy teaching happens, because students can see how to look at expressions and which clues to pay attention to (e.g. extract 7 turn 5). In addition, students can engage in collaborative efforts in providing the correct translation as in T13's lesson (extract 6 , turns $2-3 ; 5-6)$. The structure of the interaction in these sequences is akin to Mercer's [18] notion of "cumulative talk". Cumulative talk entails talking to think together. There is no question-answer or argument; speakers build on each other's contributions. Such interactions facilitate thinking together; in other words, "interthinking" [18].

In TRs lessons, this feature cannot be observed. Trainees do not use translation and try to avoid the use of mother tongue especially during whole class interactions. In addition, they tend to focus on either meaning or the form of the reading passages in the textbooks. For example, in the following extract, TR1 is doing the reading passage in the textbook. 
Extract 9. Materials mode from TR1's lesson

\begin{tabular}{|c|c|c|}
\hline 1 & TR1 & $\begin{array}{l}\text { have has had (.) good he } \\
\text { went- sorry his brothers } \\
\text { went to- went, }\end{array}$ \\
\hline 2 & Ss & {$[$ [go } \\
\hline & TR1 & $\begin{array}{l}\text { go good Ian didn't like and } \\
\text { he left- left, } \\
\text { (llooking at the passage in }\end{array}$ \\
\hline & s1 & $\begin{array}{l}\text { a puzzled way, attempting to } \\
\text { complete the sentence)) } \\
\text { not here in the passage (.) }\end{array}$ \\
\hline & TR1 & $\begin{array}{l}\text { he left, leave ok, leave } \\
\text { ((writing on the board: } \\
\text { leave-left)) hmm he went-we } \\
\text { said went, go. he finished, }\end{array}$ \\
\hline 6 & s1 & $\begin{array}{l}\text { bitirdi } \\
\text { /finished/ }\end{array}$ \\
\hline 7 & TR1 & $\begin{array}{l}\text { yes bitirdi but he wanted, } \\
\text { /finished/ }\end{array}$ \\
\hline & Ss & [ [want \\
\hline & TR1 & $\begin{array}{l}\text { yes he couldn't pass the exam } \\
\text { returned- returned, }\end{array}$ \\
\hline 10 & Ss & {$[$ [return } \\
\hline$\perp \perp$ & TR1 & return (.) he got the job, \\
\hline 12 & s2 & get \\
\hline & TR1 & good-get a job (.) changed, \\
\hline & s3 & change \\
\hline
\end{tabular}

In this extract, we can see that TR1 wants to focus on the verb forms only. During the earlier turns, he reads aloud the sentence which contains a V2 form and the students give the
V1 form in chorus. He nominates $\mathrm{S} 1$ to give the V1 form for "left" but S1 fails to answer because he apparently was not paying attention. His first reaction was trying to complete the sentence, looking for clues in the passage. TR1 clarifies the desired response with an explanation on the board and passes to the next verb - finished. S1, still not getting it this time offers the Turkish translation of the verb. TR1 not only passes the question unanswered, but also begins to provide less and less context from the passage. This can be interpreted as an attempt to avoid further misunderstandings. The focus is clearly on the form and definitely not on the meaning. There is not a dual focus as observed in Ts data.

\section{Conclusions}

The modes analysis of the data in this study brought into light the pedagogical goals and interactional features pertaining to materials mode. The following table summarizes the findings from all participants. The first column belongs to the found pedagogical goals in this study. In the second, third and fourth columns, the three resources of data are shown to facilitate comparison. If the pedagogic goal was observed in the data, a tick $(\checkmark)$ and the interactional features to fulfill that goal are summarized in parentheses. A cross $(x)$ is used to show lack of a goal.

Table 2. The Summary of Comparison across Data Sets

\begin{tabular}{|c|c|c|c|c|c|c|}
\hline Pedagogical Goals & \multicolumn{2}{|r|}{$\begin{array}{c}\text { SETT } \\
\text { (interactional features) }\end{array}$} & \multicolumn{2}{|r|}{$\begin{array}{c}\text { T's Data } \\
\text { (interactional features) }\end{array}$} & \multicolumn{2}{|r|}{$\begin{array}{c}\text { TR's Data } \\
\text { (interactional features) }\end{array}$} \\
\hline $\begin{array}{l}\text { To provide language practice } \\
\text { around a piece of material }\end{array}$ & $\checkmark$ & (IRF pattern) & $\checkmark$ & $\begin{array}{l}\text { (mostly L2, IRF pattern, no } \\
\text { insertion sequences) }\end{array}$ & $\checkmark$ & $\begin{array}{l}\text { (mostly L2, IRF pattern, } \\
\text { might be interrupted by } \\
\text { insertion sequences,) }\end{array}$ \\
\hline $\begin{array}{l}\text { To elicit responses in relation to } \\
\text { the material }\end{array}$ & $\checkmark$ & $\begin{array}{l}\text { (scaffolding, display } \\
\text { questions and form focused } \\
\text { feedback) }\end{array}$ & $\checkmark$ & $\begin{array}{l}\text { (mostly L2, echo, helpful } \\
\text { completion, offering } \\
\text { choice, cueing, etc.) }\end{array}$ & $\checkmark$ & $\begin{array}{l}\text { (not as varied in terms of } \\
\text { elicitation strategies) }\end{array}$ \\
\hline To check and display answers & $\checkmark$ & $\begin{array}{l}\text { (repair is used to correct } \\
\text { errors and give further } \\
\text { examples) }\end{array}$ & $\checkmark$ & $\begin{array}{l}\text { (mostly L2, repair both } \\
\text { directly and indirectly) }\end{array}$ & $\checkmark$ & $\begin{array}{l}\text { (mostly L2, repair both } \\
\text { directly and indirectly) }\end{array}$ \\
\hline To evaluate contributions & $\checkmark$ & $\begin{array}{l}\text { (teacher feedback is } \\
\text { form-focused, attending to } \\
\text { correctness rather than } \\
\text { content) }\end{array}$ & $\checkmark$ & $\begin{array}{l}\text { (focus on form rather than } \\
\text { meaning) }\end{array}$ & $\checkmark$ & $\begin{array}{l}\text { (focus on form rather than } \\
\text { meaning) }\end{array}$ \\
\hline To clarify when necessary & $\checkmark$ & & $\checkmark$ & (mostly in L1) & $\checkmark$ & $\begin{array}{l}\text { (try to avoid L1, especially } \\
\text { with whole class) }\end{array}$ \\
\hline $\begin{array}{c}\text { To make the material accessible to } \\
\text { students }\end{array}$ & $x$ & & $\checkmark$ & $\begin{array}{l}\text { (mostly in L1, change of } \\
\text { footing) }\end{array}$ & $\checkmark$ & $\begin{array}{l}\text { (mostly in L1, with } \\
\text { individual students, in L2 if } \\
\text { with whole class, no change } \\
\text { of footing) }\end{array}$ \\
\hline $\begin{array}{l}\text { To warrant full comprehension of } \\
\text { the texts in the material (line by } \\
\text { line analysis) }\end{array}$ & $x$ & & $\checkmark$ & $\begin{array}{l}\text { (translation, cumulative } \\
\text { talk, strategy training, } \\
\text { modeling by the teacher, } \\
\text { dual focus) }\end{array}$ & $x$ & \\
\hline
\end{tabular}


Walsh [26] developed SETT framework in the UK, based on English lessons that took place in the western culture. The similarities found between SETT and other studies which used SETT motivate us to explore further the possibility of determining universal features for English lessons as institutional discourse. Markee [17] emphasized the need to "engage in comparative re-production research in order to make broad statements about the generality and prototypicality of the qualitative organization of particular practices across languages, cultures and institutional contexts" (p. 1). The implications of discovering such prototypes would appeal to the researcher both as a language learner and as a teacher.

More appealing than that, however, are the differences that were manifested by the analysis. The fact that there were differences in the way materials are conducted in the data from the descriptions in SETT proves the existence of context-specific features of language lessons. Like any community, classroom community is affected from the culture in which it takes place. People bring their backgrounds to the situation. Since the onset of post method condition, there has been a shift of focus from the imposed ways of teaching and learning to the "localized" practices [14]. Thus, "while making themselves aware of principles and practices of the colonial construct of method, teachers rely mostly on context-sensitive local knowledge to identify problems, find solutions, and try them out to see what works and what does not in their specific context" [13]. The most important two features that met the eye in this study were the use of L1 and the line-by-line analysis of the textbook passages. These can have stemmed from the local experience of the teachers. Ișık [11] discusses that since the times of the Ottoman empire, Turkish culture of language teaching "equates language education with studying formal aspects of a target language and consists of mechanical practice of the isolated formal aspects of a target language at the sentence level" [11]. This understanding often entails making sure that each and every word in the textbook must be taught explicitly - usually through word-by-word translation. Despite the fact that translation is generally discouraged in current language teacher education in Turkey and the textbook presents many communicative tasks based on the passages, the teachers take a completely different path and insist on these practices. Thus, it might be the time to put aside prescriptive attitudes and seek ways of understanding the benefits that the teachers see in such procedures. As mentioned earlier, the inevitability of L1 in foreign language classes is well-established by previous research. Although SETT does not account for the use of $\mathrm{L} 1$, it has been proved once more with this study that $\mathrm{L} 1$ is an inevitable aspect of foreign language classes.

The differences between the T's Data and the TR's Data also highlight and reinforce the argument towards the need of accepting what occurs in the language classrooms as a reference point to inform teacher education. On one hand, the local knowledge seems to be not available to the trainees yet, since they neither use L1 nor do line-by-line analysis.
On the other hand, they seem to be making special effort to avoid such practices in their demo lessons. The possible reason for this could be due to their training which indoctrinated them according to the Western sense of teaching and learning. They preferred to use less mother tongue compared to the teachers. They shunned from using Turkish with the whole class, in a way hiding it from the rest of the class. One caveat is that for the teachers, the researcher is merely an observer and a researcher in the class. On the other hand, the trainees see the researcher as not only an observer, but also a representative of the formal training they had received from the university. Hodkinson and Hodkinson [8] draw attention to the effect that tutors and instructors might have on the classroom decisions of trainee teachers. Therefore, it must be considered that the observer's effect could have been stronger on trainees' choices. The line-by-line translation did not exist in the TR's Data. In fact, the trainees rarely deviated from the textbook activities. One explanation can be that the trainees lack the professional experience and confidence and stick to safe procedures rather than venturing new ways of using the textbook. There is considerable evidence that teachers become more flexible and versatile in their pedagogical decisions as they gain experience [7]. In addition, the lack of adaptation might indicate a view of the textbook as superior factor. This impression is also reinforced by the fact that the TR's Data lacks the change of footing that was found in T's Data. Trainees seem to prefer aligning themselves with the book and never step across to stand against the book, together with the students.

Of course all these impressions need to be validated with more focused research. One implication is that the teacher education that is provided at Muğla Sitkı Koçman University needs to be reconsidered in the light of these findings. Secondly, the emergent picture as a result of this study gave us a description of what is there to investigate. In that sense, this study has paved the way for future research to contribute to the localization of the language teaching profession as well as finding out the universal characteristics of the institutional discourse in ELT lessons.

\section{REFERENCES}

[1] Akyol, T. (2014). An Analysis of Teaching Practices and Classroom Interaction of Native and Non-Native Teachers of English. (Unpublished MA Thesis). Akdeniz University: Antalya.

[2] Allwright, R. L. (1981). What do we want teaching materials for? ELT Journal, 36(1), 5-18.http://eltj.oxfordjournals.org/c ontent $/ 36 / 1 / 5$.abstract

[3] Ellis, R. (2012). Language teaching research and language pedagogy. West Sussex: John Wiley \& Sons.

[4] Elridge, J. (1996). Code-switching in a Turkish secondary school. ELT Journal, 50(4), 303-311.http://eltj.oxfordjournal s.org/content $/ 50 / 4 / 303$.abstract 
[5] Ghosn, I. (2014). Talking like texts and talking about texts: How some primary school coursebook tasks are realized in the classroom. In B. Tomlinson (Ed.), Developing Materials for Language Teaching 2nd Ed.: Chapters from the first edition (p. 291-305). London: Bloomsbury.

[6] Harmer, J. (2008). The practice of English language teaching. 4th Ed. London: Pearson Longman.

[7] Hayes, D. (1999). Decisions, decisions, decisions: The process of 'getting better at teaching'. Teacher Development, 3(3), 341-354. DOI: 10.1080/13664539900200090

[8] Hodkinson, H., \& Hodkinson, P. (1997). Micro-politics in initial teacher education: Luke's story. Journal of Education for Teaching: International Research and Pedagogy, 23(2), 119-130.

[9] Humphries, S. (2014). Codeswitching in Two Japanese Contexts. In Barnard, R. \& McLellan, J. (Eds.). Codeswitching in University English-Medium Classes: Asian perspectives. Multilingual Matters: Bristol. Pp.65-76.

[10] Hutchinson, T., \& Torres, E. (1994). The textbook as agent of change. ELT Journal, 48(4), 315-328.http://eltj.oxfordjourna ls.org/content/48/4/315.abstract

[11] [11]Işsk, A. (2011). Language education and ELT materials in Turkey from the path dependence perspective. Hacettepe Üniversitesi Ĕ̌itim Fakültesi Dergisi, 40, 256-266. http://eric.ed.gov/?id=EJ936725

[12] Kiasi, M.A., Hemmati, F. (2014). The importance of 'teacher talk' in teaching EFL writing. Porta Linguarum, 22, 95-108.

[13] Kumaravadivelu, B. (2003). Critical language pedagogy: A postmethod perspective on language teaching. World Englishes, 22(4), 539-550. http://onlinelibrary.wiley.com/doi /10.1111/j.1467-971X.2003.00317.x/abstract

[14] Kumaravadivelu, B. (2006). TESOL methods: Changing tracks, challenging trends. TESOL Quarterly, 40(1), 59-81. http://onlinelibrary.wiley.com/doi/10.2307/40264511/abstrac $\mathrm{t}$

[15] Lee, E.H. (2010). An analysis of online lecture discourse of a Korean NNS teacher and an American NS teacher. Linguistic Research, 27(1), 209-229. http://isli.khu.ac.kr/journal/conten t/data/27_1/9.pdf

[16] Macaro, E. (2005). Codeswitching in the L2 classroom: A communication and learning strategy. In E. Llurda (Ed.), Non-native language teachers: Perceptions, challenges and contributions to the profession (p. 63-84). New York: Springer.

[17] Markee, N. (2015). Are replication studies possible in qualitative second/foreign language classroom research? A call for comparative re-production research. Language Teaching. Available on CJ02015.doi:10.1017/50261444815 0000099
[18] Mercer, N. (2000). Words and minds: How we use language to think together. New York: Routledge.

[19] Miri, M., \& Qassemi, Z. (2015). Delving into EAP teachers' classroom behavior: Construction or obstruction of learning opportunities in EFL context. The Journal of Teaching English for Specific and Academic Purposes, 3(1), 149-164.http://espeap.junis.ni.ac.rs/index.php/espeap/article/ view/206

[20] Sali, P. (2014). An analysis of the teachers' use of L1 in Turkish EFL classrooms. System, 42, 308-318.http://www.s ciencedirect.com/science/article/pii/S0346251X14000037

[21] Sarıçoban, A. (2010a). Problems encountered by student teachers during their practicum studies. Procedia Social and Behavioral Sciences, 2, 707-711. http://www.sciencedirect.c om/science/article/pii/S187704281000128X

[22] Sarıçoban, A. (2010b). Should native language be allowed in foreign language classes? Egitim Arastirmalari-Eurasian Journal of Educational Research, 38, 164-178. http://www.ejer.com.tr/?git=22\&kategori $=85 \&$ makale $=682$

[23] Sato, A. (2012). Effective teacher talk on building rapport with students. Humanities Research Otaru University of Commerce, 123, 231-267. Retrieved March, 21, 2014 from http://barrel.ih.otaru-uc.ac.jp

[24] Seedhouse, P. (1997). The case of the missing "No": The relationship between pedagogy and interaction. Language Learning, 47(3), 547-583. http://onlinelibrary.wiley.com/doi /10.1111/0023-8333.00019/abstract

[25] Üstünel, E. (2009). The sequential organization of code-switching in EFL classrooms. Saarbrücken: Verlag Dr. Müller.

[26] Walsh, S. (2006) Investigating classroom discourse. New York: Routledge Publishing.

[27] Wang, P.L. (2012). The investigation of classroom modes and interactional features in young learners' English classrooms. (Unpublished master's thesis), Department of Applied English, School of Education and Applied Languages, Ming Chuan University, Taiwan.

[28] Willis, J. (1992). Inner and outer: Spoken discourse in the language classroom. In M. Coulthard (Ed.), Advances in spoken discourse analysis (p. 162-182). London: Routledge.

[29] Wooffitt, R. (2005). Conversation analysis and discourse analysis: A comparative and critical introduction. London: Sage.

[30] Yatağanbaba, E., \& Yıldırım, R. (2015). EFL teachers' code-switching in Turkish secondary EFL young language learner classrooms. International Journal of Linguistics, 7(1), 82-101. 